\title{
OBSERVACIONES SOBRE LA INMIGRACIÓN MAGREBÍ A TRAVÉS DE LA CORRESPONDENCIA
}

\author{
Juan David Sempere Souvannavong
}

\section{RESUMEN}

Murcia es, después de Barcelona y Madrid, una de las provincias de España donde residen más inmigrados marroquíes. Contrariamente a lo que sucede en éstas, en la región de Murcia la inmigración africana está muy polarizada por el sector agrario en el que trabajan una gran mayoría de los inmigrados magrebíes.

A ellos se dedica, cada noche, un programa de radio en el que, en árabe y en castellano, se dan noticias, consejos y entrevistas relativos al mundo de la inmigración. Desde 1992 este programa, convertido en un punto de referencia importante para la población inmigrada, ha recibido varios cientos de cartas en las que los inmigrados piden consejo y cuentan sus principales problemas.

La lectura de estas cartas, analizadas como fuente de información, permite conocer nuevos aspectos de la inmigración en una de las regiones donde está más desarrollada.

\section{RÉSUMÉ}

Aprés Barcelone et Madrid, Murcie est une des provinces d'Espagne où habitent le plus d'immigrés marroquins. Contrairement à celles-ci, dans la région de Murcie l'immigration est essentiellement polarisée dans le secteur agraire, domaine dans lequel travaille une grande majorité des immigrés maghrébins.

Tous les soirs, un programme de radio leur est dédié. Dans cette émission on donne, en arabe et en espagnol, des nouvelles, des conseils et des entrevues concernant le monde de l'immigration. Depuis 1992 ce programme, devenu un point de référence important pour la population immigrée, a reçut plusieurs centaines de lettres dans lesquelles les immigrés demandent des conseils et racontent leurs problèmes.

La lecture de ces lettres nous a permis de connaître des aspects nouveaux de l'immigration dans une des régions où elle est plus développée.

\section{Introducción}

En el transcurso de esta década se han multiplicado en España los estudios sobre la inmigración extracomunitaria, mientras que tales investigaciones eran casi inexistentes con anterioridad. Las encuestas, las estadísticas de residencia y de trabajo, los datos de las 
regularizaciones y de los contingentes autorizados anualmente desde 1993, han sido las fuentes más empleadas para el análisis de un fenómeno que no ha dejado de crecer en los últimos años. En este artículo se proponen unas observaciones extraídas de otra fuente hasta ahora inexplorada, las cartas que los inmigrados africanos residentes en una de las zonas donde son más numerosos — la provincia de Murcia-, han escrito desde 1992 a un programa de radio. Así, intentaremos observar desde un nuevo punto de vista la situación de este colectivo.

\section{«Tertulia entre Hermanos»}

Onda Regional de Murcia es una emisora pública en la que desde junio de 1992 se emite un espacio íntegramente dedicado a la población inmigrada africana ${ }^{1}$ : «Tertulia Entre Hermanos». Este programa se realiza en directo cada día y se escucha en toda la provincia de Murcia, en una parte importante de las de Almería, Albacete y Alicante e incluso en zonas del noroeste de Argelia.

Cada noche, durante 30 minutos, con un horario que ha cambiado varias veces desde 1992, se realiza, en árabe y en castellano, este espacio en el que se abordan los aspectos que más preocupan a los inmigrados: las dificultades laborales o sindicales, el problema de la vivienda, la reagrupación familiar y sobre todo los cupos de contingentes de trabajadores extranjeros que autoriza cada año el Gobierno de España y por los que existe un verdadero interés en los colectivos en situación irregular. Además se dan noticias, tanto generales como relativas a la inmigración, se realizan entrevistas con personalidades que tienen que ver con este mundo, se dan clases de castellano, se responde a llamadas telefónicas y se contesta a las cartas recibidas. De manera puntual también se dan consejos médicos y temporalmente se abordan temas relacionados con las culturas árabe y española.

Esta iniciativa radiofónica ha sido el objeto, desde antes de su aparición, de más de cincuenta artículos de prensa aparecidos en diarios locales y nacionales, sobre todo en el mes de junio cuando el programa celebra su cumpleaños organizando una fiesta o un concierto para la población magrebí.

La audiencia que esta emisión tiene entre la población inmigrada puede ser calificada de muy alta. Una encuesta publicada en un estudio sobre la inmigración en la región de Murcia [CES, 1997: 429-430] indicaba en 1997 que más de un 80\% por ciento de los inmigrados entrevistados conocían el programa; de ellos casi las tres cuartas partes lo escuchaban a veces o siempre y las dos terceras partes lo valoraban positivamente. Aunque es una encuesta elaborada a partir de un número reducido de entrevistas, no cabe duda de que se trata de unos índices de audiencia y de aceptación que raras veces puede alcanzar cualquier medio de comunicación entre el colectivo al que se dirije.

\section{La importancia de la inmigración en la región de Murcia}

Estas circunstancias hacen que el programa sea casi un observatorio permanente de la inmigración en el centro de una de las zonas donde el número de magrebíes es más importante y en una de las regiones donde la presencia de mano de obra inmigrada se ha generalizado en un sector de la economía como las nuevas agriculturas intensivas.

1 Ha habido intentos de realizar programas similares, concretamente en Barcelona donde reside el colectivo de marroquíes más numeroso de España. Desde abril de 1998 Canal 7 emite desde Málaga un programa de radio parecido. Hasta entonces «Tertulia entre Hermanos» había sido el único programa en su género en toda España. 
Tras la regularización extraordinaria de extranjeros que se desarrolló durante en 1991 en España, Murcia se encontró con que era, después de Barcelona y Madrid, la provincia donde más marroquíes y magrebíes residían [López, 1996: 4]. Y es que en este proceso Murcia fue la provincia donde más personas se regularizaron en el sector agrario, y, depués de Cataluña y la Comunidad de Madrid, la autonomía donde más personas se regularizaron en general. Más de un $80 \%$ de las 4.000 solicitudes que se aceptaron en Murcia, pertenecían al sector agrario; así, esta región se ha transformado junto con Barcelona, Almería y Cáceres en una de las cuatro provincias con más inmigración agraria.

A nivel municipal Torre Pacheco (Murcia) es, justo después de El Egido (Almería), el municipio de España donde más marroquíes trabajan en agricultura.

Estas circunstancias, que no han variado en el transcurso de la década ${ }^{2}$, demuestran la importancia que tiene esta provincia — sobre todo en los municipios de Cartagena, Murcia, San Javier y Torre Pacheco- por el volumen de su inmigración africana y justifican la existencia de un programa de radio dedicado exclusivamente a ellos.

\section{Las cartas recibidas en «Tertulia entre Hermanos»}

Uno de los aspectos sin duda interesante para el estudio de la inmigración en la región de Murcia, es el análisis de las cartas que se reciben en este programa. Desde sus inicios muchos inmigrados se han dirigido por carta a «Tertulia entre Hermanos» para agradecer la atención de los organizadores, pedir consejo, contar sus problemas o simplemente saludar a conocidos. La inmensa mayoría de las cartas están escritas en árabe, pero a fin de poder ser contestadas en el programa están todas resumidas en castellano, lo que nos ha permitido su estudio.

Estas cartas forman una valiosa fuente de información que revela con sinceridad, muchos de los detalles, temores y problemas con los que los inmigrados magrebíes, irregulares o con permiso de trabajo, se tienen que enfrentar en su vida cotidiana.

Entre 1993 y 1996 se han recibido unas 600 cartas, pero desafortunadamente desde entonces su número ha descendido enormemente hasta hacerse incluso bastante raras. Según los realizadores del programa esta situación se debe al aumento de las llamadas telefónicas a las que los inmigrados se han acostumbrado. Antes y después del programa, cuando saben que los responsables están en la emisora, se reciben varias decenas de llamadas en las que se plantean directamente las cuestiones.

El perfil medio de las personas que se dirigen a este programa es evidentemente parecido al de los inmigrados en Murcia; invariablemente el de un hombre adulto, marroquí, que vive en el campo y que trabaja de peón en la agricultura. Todos los que escriben obviamente saben leer y escribir en árabe, pero no es raro que en las cartas se indique que han sido redactadas de manera conjunta, generalmente por los mismos que escuchan, en grupo, el programa. A lo largo del tiempo se observa un ligero aumento de los mensajes escritos en castellano, pero demasiado pequeño como para deducir que responde directamente a un incremento del número de inmigrados que escriben castellano. En cualquier caso, por los remites y por la manera de escribir la dirección de la emisora, no parece que muchos empleen a menudo el alfabeto latino. Por su parte el número de mujeres que se han dirigido al programa es extremadamente reducido ${ }^{3}$ lo que refleja fielmente la altísima sobremasculinidad que hay entre los inmigrados de la región de Murcia.

2 Murcia es, después de Cataluña y Madrid, la autonomía en la que, cada año, más solicitudes se suelen presentar para los contingentes de trabajadores extranjeros.

3 La primera carta de una mujer aparece en junio de 1993, cuando el programa lleva un año emitiéndose y ya se ha recibido más de 170 cartas. 
La estructura de las cartas se repite en la mayoría de ellas. Además de plantear las cuestiones que les preocupan, los inmigrados solicitan a menudo canciones y piden que se salude a conocidos de otras poblaciones e incluso de otros países. Una de las cosas que sorprenden es la cantidad de agradecimientos que, en un lenguage a menudo muy poético, dedican al programa y que en ocasiones ocupan la mayor parte de la carta. Esto demuestra «la importancia que conceden los magrebíes a un gesto de atención a su favor hecho desde las instancias públicas» [CES, 1997: 429].

\section{El origen geográfico de las cartas}

Entre 1992 y 1996 se han contabilizado 593 cartas, el origen de éstas revela las zonas donde hay más inmigrados y donde el programa tiene mayor influencia.

Cuadro

\begin{tabular}{|l|r|l|r|}
\hline Lugar de origen de las cartas & Total & Lugar de origen de las cartas & Total \\
\hline Alhama de Murcia & $\mathbf{1 2}$ & San Javier & 37 \\
Cartagena & $\mathbf{8 4}$ & Torre Pacheco & $\mathbf{1 3 8}$ \\
Aljorra, La & 24 & Balsicas & 53 \\
Cartagena & 11 & Dolores de Pacheco & 20 \\
Pozo Estrecho & 30 & Roldán & 10 \\
Fuente Álamo & $\mathbf{2 0}$ & Torre Pacheco & 45 \\
Lorca & $\mathbf{1 3}$ & Totana & $\mathbf{1 2}$ \\
Murcia & $\mathbf{1 4 0}$ & Resto de Murcia & $\mathbf{4 1}$ \\
Martínez del Puerto, Los & 70 & Alicante & $\mathbf{1 3}$ \\
Valladolises & 39 & Resto de España & $\mathbf{6}$ \\
San Javier & $\mathbf{7 4}$ & Extranjero & $\mathbf{2 1}$ \\
Mirador, El & 34 & Origen desconocido & $\mathbf{1 9}$ \\
\cline { 2 - 3 } & & TOTAL & $\mathbf{5 9 3}$ \\
\hline
\end{tabular}

Nota: En el cuadro sólo se indican los lugares de origen de las cartas que se repiten más de diez veces durante el periodo analizado (1992-96). En negrita los municipios y los agrupamientos que hemos realizado para la regiones situadas fuera de Murcia.

Lo que se observa es que una mayoría muy significativa de las cartas no proviene de las ciudades o de los pueblos importantes como Torre Pacheco, San Javier, Cartagena o Murcia que son las capitales de los municipios donde más se ha desarrollado la inmigración. Los orígenes de las cartas son más bien pequeñas pedanías de los municipios mencionados, situadas principalmente en el sureste de la provincia: el Campo de Cartagena. Una parte importante de estas pedanías se localizan en la salida de Cartagena a un lado y otro de la autovía que va a Murcia, mientras que una segunda área de estos pequeños pueblos está en los alrededores de San Javier y de Torre Pacheco. Evidentemente no todas las poblaciones han sido el origen de un número importante de cartas, hay que mencionar de manera especial, los Martínez del Puerto, Balsicas, Torre Pacheco y Valladolises que son, por este orden, los pueblos de donde más cartas se han recibido; éstos acumulan más de una tercera parte de las cartas recibidas por la emisora en cuatro años. Estas poblaciones están separadas por apenas unas decenas de kilómetros y parecen ser el centro de la presencia magrebí en el Campo de Cartagena y en la provincia de Murcia. 


\section{Los problemas revelados por las cartas}

La lectura de una parte de esta correspondencia ha permitido observar las cuestiones planteadas por los inmigrados y crear una tipología de los problemas que más han aparecido. Reagrupándolos se puede decir que los temas que más se han abordado son los problemas de documentación, de vivienda y de trabajo; de una manera más detallada los inmigrados se quejan en sus cartas de:

— Los aspectos relativos a «los papeles»; principalmente por el excesivo tiempo que tarda la administración (a veces hasta ocho meses) en responder a las solicitudes de permiso y de renovación. Este retraso no permite a los inmigrados regularizar su situación, y sin la documentación necesaria no pueden entrar en España una vez que han salido. Es algo de lo que se lamentan especialmente ya que este hecho, según ellos sólo imputable a la lentitud de la administración, les impide volver a su país de origen durante las vacaciones o ver a sus familias cuando circunstancias como bodas o funerales realmente lo exigen, sin el riesgo de no poder volver a entrar luego en España.

La mayoría de las veces simplemente se piden explicaciones sobre muchas cuestiones relativas a los «papeles»: renovación del permiso de trabajo y de residencia, convalidación del permiso de conducir del país de origen, qué hacer en caso de perder el pasaporte y sobre todo lo que respecta a los contingentes que cada año pone el gobierno (número de permisos que tendrá el cupo, plazos de presentación, quién y cómo puede solicitar un permiso...). Al ser la regularidad residencial y laboral un aspecto trascendental en la vida de los inmigrados, corren muchísimos rumores acerca de posibles regularizaciones o del contingente de trabajadores extranjeros a autorizar, rumores a menudo alentados por las organizaciones que introducen inmigrantes y que les hacen creer que no tendrán problemas para legalizar su situación. Los responsables del programa se informan de la realidad y la mayoría de las veces tienen que desmentir estos rumores.

- Los problemas de alojamiento. Sucede que los magrebíes con frecuencia no tienen lugar donde alojarse, pero la mayoría de las quejas se deben sobre todo a las condiciones infrahumanas en las que muchos de ellos están obligados a vivir. Barracas en medio del campo sin ningún servicio, sin electricidad y sin agua corriente, por las que sin embargo deben pagar un alquiler demasiadas veces excesivo. También se quejan de las dificultades que tienen para encontrar alguien que les quiera alquilar una vivienda, a pesar de tener solvencia económica. En este sentido la organización «Murcia Acoge» lanzó en 1997 una campaña cuyo lema era «mi amigo necesita casa, ¿la tienes tú?». Según responsables de esta asociación consultados, el disponer de una vivienda digna es el problema actual de más urgente solución que tiene el colectivo inmigrado en su conjunto.

- Los problemas de trabajo. Este apartado engloba todo lo relativo al comportamiento de los empresarios (generalmente debido a que no hacen contrato a los trabajadores), a la discriminación que hay con respecto a los españoles (realizan sistemáticamente las tareas más duras) y a la explotación a la cual se sienten sometidos (llegan a trabajar 9 horas por menos de 3.000 pts.).

De los grandes grupos de problemas que hemos señalado hay que destacar un hecho, y es que a pesar de la situación tan difícil, las cuestiones relativas a las reivindicaciones y a las discriminaciones son menos importantes que las relativas a la situación administrativa y al alojamiento. Las carencias sobre «los papeles» y la vivienda parecen ser los aspectos 
que consideran más urgentes y angustiosos a juzgar tanto por lo que dicen las cartas como por el tono en que están redactadas.

Fuera de estos tres grandes aspectos, también hay otros temas que no pueden ser englobados y que sin embargo tienen cierta importancia y se repiten a menudo.

Así, hay denuncias de engaños, normalmente de particulares que les han estafado en alguna compra y de abogados que cobran mucho dinero por encargarse de sus demandas de regularización.

Un número considerable de cartas están dedicadas a pedir ayuda respecto a un amigo o un pariente perdido, el hecho de tener una audiencia tan elevada ha permitido a los responsables del programa facilitar numerosos reencuentros, a veces debidos sencillamente a que los «desaparecidos» habían sido detenidos y no sabían a qué número de teléfono llamar.

Otro problema importante que revelan las cartas es la falta de unión que hay entre los inmigrados africanos. Esta desunión se debe normalmente a los nacionalismos, a la política que practican algunas asociaciones y sobre todo a la rivalidad que hay entre inmigrados regularizados y los que están en situación irregular: los primeros acusan a los últimos de ser una competencia desleal en el trabajo, y los últimos acusan a los primeros de ser poco solidarios una vez que han conseguido el permiso de trabajo.

Finalmente destacaremos aquellas cartas, bastante numerosas, en las que se pide a la comunidad inmigrada que cuide su imagen ante la sociedad española ya que «el error» de una persona puede repercutir en la imagen de todo el colectivo.

\section{Conclusión}

El análisis de la correspondencia de los inmigrados ha revelado ser muy valioso para el estudio de la inmigración, aunque como en este caso la correspondencia se realice con un programa de radio.

Estas cartas nos han permitido exponer cuales son las cuestiones que más inquietan a los magrebíes que residen en la zona de audiencia de este programa. Con ello hemos confirmado que la inmigración es un fenómeno esencialmente reciente y con graves problemas de urgente solución. La composición demográfica, la ausencia casi absoluta de mujeres, la excepcionalidad de las cartas en castellano, la precariedad que éstas han revelado en los empleos y la prioridad dada a los problemas de regularidad y de vivienda ante las reivindicaciones y las discriminaciones, son factores que se han observado en las cartas y que revelan hasta qué punto la integración de los inmigrados está todavía, en una de sus regiones más importantes, en sus primeros balbuceos. Está en una fase en la que los inmigrados viven con temor ante la sociedad en la que se desenvuelven, trabajan en condiciones miserables y en la que las quejas son muy inferiores a lo que su situación permitiría suponer en cualquier otro colectivo.

\section{Bibliografía}

AVELLÁ REUS, L. (1995): «Competencia y complementariedad en el mercado de trabajo entre nacionalidades e inmigrantes: el caso español», Seminario. Inmigración, empleo e integración social. Universidad Menéndez Pelayo, Santander, $31 \mathrm{pp}$.

BEL ADELL, Carmen (1996): Realidad social de la inmigración. Condiciones de vida del inmigrante africano en el municipio de Murcia, Ed. Universidad de Murcia, Murcia, 179 p.

CEBRIÁN, Aureliano (1993): «Las inmigración magrebí en la Comunidad de Murcia: su inserción en el ámbito laboral», Awraq, no XIV, pp. 199-225. 
CHECA, Francisco (1995): Invernaderos e inmigrantes: el problema de la adaptación de un colectivo marginal, Proyecto subvencionado por la Dirección General de Migraciones, Ministerio de Asuntos Sociales, Madrid.

CHILLÓN CORBALÁN, Juan Luis (1997): La inmigración en la Región de Murcia. Análisis de la situación actual: problemática, inmigrantes en la ilegalidad, condiciones necesarias para una integración plena, Ed. Consejo Económico y Social (CES), Colección estudios Nº 6, Murcia, 685 p.

FERRIERI, Gaetano (1996): «Aspectos socio-económicos de las migraciones recientes en España en el contexto de la Europa meridional. Elementos para una posible teoría», Investigaciones Geográficas, $\mathrm{n}^{\mathrm{o}} 16$, pp. 61-92.

GIMÉNEZ ROMERO, Carlos (Dir.) (1992): La inmigración y el mercado de trabajo agrícola en la Comunidad Valenciana, Informe de investigación patrocinada por el Institut Valenciá de Estudis e Investigació.

GOZÁLVEZ PÉREZ, Vicente (Dir.) (1995): Inmigrantes marroquíes y senegaleses en la España mediterránea, Valencia: Ed. Consellería de Trabajo, 440 p.

LÓPEZ GARCÍA, Bernabé (Dir.) (1996): Atlas de la inmigración magrebí en España, Madrid: Ed. UAM, 262 p.

Ministerio de Trabajo y Asuntos Sociales (1996): Anuario de Migraciones. 1996, Dirección General de Ordenación de las Migraciones, Madrid, 687 p.

SEGRELLES SERRANO, J.A. y GÓMEZ LÓPEZ, J.D. (1995): «Agricultura intensiva y mano de obra marroquí en el Campo de Dalías (Almería)», Boletín del Instituto de Estudios Almerienses, $\mathrm{n}^{\mathrm{o}} 14$, pp. 155-172.

VILAR, Juan Bautista (1994): Murcia: Frontera demográfica en el Sur de Europa, Ed. Universidad de Murcia, Murcia, 176 pp. 